\title{
Case management for patients with chronic systolic heart failure in primary care: The HICMan exploratory randomised controlled trial
}

\author{
Frank Peters-Klimm*1, Stephen Campbell1,2, Katja Hermann'1, Cornelia U Kunz³, Thomas Müller-Tasch4, \\ Joachim Szecsenyi ${ }^{1}$ for the Competence Network Heart Failure
}

\begin{abstract}
Background: Chronic (systolic) heart failure (CHF) represents a clinical syndrome with high individual and societal burden of disease. Multifaceted interventions like case management are seen as promising ways of improving patient outcomes, but lack a robust evidence base, especially for primary care. The aim of the study was to explore the effectiveness of a new model of CHF case management conducted by doctors' assistants (DAs, equivalent to a nursing role) and supported by general practitioners (GPs).

Methods: This patient-randomised controlled trial (phase II) included 31 DAs and employing GPs from 29 small officebased practices in Germany. Patients with CHF received either case management $(n=99)$ consisting of telephone monitoring and home visits or usual care $(n=100)$ for 12 months. We obtained clinical data, health care utilisation data, and patient-reported data on generic and disease-specific quality of life (QoL, SF-36 and KCCQ), CHF self-care (EHFSCBS) and on quality of care (PACIC-5A). To compare between groups at follow-up, we performed analyses of covariance and logistic regression models.

Results: Baseline measurement showed high guideline adherence to evidence-based pharmacotherapy and good patient self-care: Patients received angiotensin converting enzyme inhibitors (or angiotensin- 2 receptor antagonists) in $93.8 \%$ and $95 \%$, and betablockers in $72.2 \%$ and $84 \%$, and received both in combination in $68 \%$ and $80 \%$ of cases respectively. EHFSCBS scores (SD) were 25.4 (8.4) and 25.0 (7.1). KCCQ overall summary scores (SD) were 65.4 (22.6) and 64.7 (22.7). We found low hospital admission and mortality rates. EHFScBS scores (-3.6 [-5.7;-1.6]) and PACIC and 5A scores (both 0.5, [0.3;0.7/0.8]) improved in favour of CM but QoL scores showed no significant group differences (Physical/Mental SF-36 summary scores/KCCQ-os [95\%Cl]: -0.3 [-3.0;2.5]/-0.1 [-3.4;3.1]/1.7 [-3.0;6.4]).

Conclusions: In this sample, with little room for improvement regarding evidence-based pharmacotherapy and CHF self-care, case management showed no improved health outcomes or health care utilisation. However, case management significantly improved performance and key intermediate outcomes. Our study provides evidence for the feasibility of the case management model.
\end{abstract}

Trial registration number: ISRCTN30822978

\section{Background}

Chronic (systolic) heart failure (CHF) is a "common, disabling, deadly, and costly disease" [1] characterised by hospital admissions due to clinical deterioration. New treatment and care strategies focus on the prevention of

* Correspondence: frank.peters@med.uni-heidelberg.de

1 Department of General Practice and Health Services Research, University Hospital Heidelberg, Heidelberg, Germany

Full list of author information is available at the end of the article admissions and improvement of prognosis. Effective knowledge transfer, for example the adherence of physicians to clinical practice guidelines (CPG) [2] and patients to treatment regimens [3], is regarded as a key issue for better patient outcomes.

For improved outcomes, multifaceted interventions are regarded as essential and many approaches have been tested. To foster comparability between the related studies, a taxonomy for chronic disease/case management has 
been suggested accounting for 8 domains (i.e. Patient population; Intervention recipient and content; Delivery personnel; Method of communication; Intensity and Complexity; Environment; Clinical outcomes) [4]. Accordingly, trials have been evaluated with different focuses, e.g. on changes in the organisation and delivery of care involving trained nurses [5], pharmacists [6], and call-centres providing home-based or telephone support or telemedicine $[7,8]$, with mixed, but promising results. Ambulatory case management programmes "characterized by intensive post-discharge monitoring by a case manager (usually a nurse)" [4] have demonstrated positive effects on quality of life and mortality in three to six months follow-up, but the results are inconsistent for a longer follow-up [9-13].

Most studies have been conducted with acute patients enrolled in hospital or shortly after discharge rather than in primary care. Implementation of a primary care-based case management model in small-size office-based practices in Germany, which are led privately by primary care physicians, is problematical $[14,15]$. Unlike in many countries (e.g. UK and the US), practices in Germany do not have large teams or combinations of skill mix, i.e. they consist primarily of GPs (61\% are solo practitioners [16]) and doctors' assistants (equivalent to a nursing role) [17]. German patients do not register with a single general practice and have free access to secondary care. Patients with complex chronic conditions like CHF receive regular follow-up in specialist care. Nevertheless, general practices are the primary caregivers and first point of contact for the majority of heart failure patients and represent a practical target for delivering case management interventions aimed at improved outcomes.

A comprehensive framework of chronic illness care suitable in primary care is the chronic care model (CCM), which aims to improve the care of patients by integrating a number of elements into a package designed to foster more productive interactions between trained, proactive teams and well-informed, motivated patients. The six elements that need to be addressed appropriately for providing high-quality care to patients within this model are delivery system design, self-management support, decision support, clinical information systems, community resources, and healthcare organisation [18].

The aim of this study was to evaluate such a case management model in comparison to usual care because no studies have applied a complex primary care-based model for heart failure patients in Germany.

\section{Methods \\ Design}

This study was part of an exploratory patient-randomised controlled trial (ISRCTN30822978) conceptualised as a phase II trial according to the framework of designing and evaluating complex interventions [14,15]. As such, qualitative methodologies were undertaken alongside the trial, to provide supplementary evidence $[17,19]$. The trial conformed to the principles outlined in the Declaration of Helsinki [20] and was approved by the institutional review boards of the local medical faculty of the university and the Medical Association of the federal state Baden-Württemberg in Germany. The full protocol of this trial has been published elsewhere [21]. The trial was an independent project within subproject 10 "Quality of Life" within the German "Competence Network Heart Failure", a nationwide research network that bundles the scientific expertise in a large-scale research network, sponsored by the Federal Ministry of Education and Research http://www.knhi.de[22]. Its aims include the coordination of basic and applied clinical research.

\section{Participants - Recruitment and Assignment}

We invited general practitioners (GPs) to participate in the study through a single mail-out to primary care practices in one region of Northern Baden, Germany [21]. Interested GPs were eligible for participation if they were certified as primary care physicians or equivalent and practiced as statutory health insurance affiliated physicians. To be eligible for inclusion, doctors' assistants, all employed by the GP, had to have completed at least two years of their formal training (which consists of a three years practice-based, vocational training with part-time attendance at a vocational school) [21].

Eligible patients were adults with ascertained left ventricular systolic dysfunction (left ventricular ejection fraction of $45 \%$ or less), as described in detail elsewhere [21]. We obtained written informed consent from all participating health professionals and patients.

There is an assumed prevalence of patients with at least moderately impaired left ventricular function of $1 \%$ [1]. GPs were expected to include all eligible patients. Anticipating the difficulties with screening and patient inclusion, we estimated an average of 5 patients per GP (taking into account an average list size of 800 patients per GP in Germany) [23]. Case finding consisted of three strategies, i.e. brainstorming, opportunistic presentation for consultation by patients, and screening Electronic Medical Records using ICD-Codes (International Classification of Diseases) for (potential) heart failure (e.g. I 11* for Hypertensive Heart Disease, I 25* for CHD, I 40 for Myocarditis, I 42* for Cardiomyopathy, I 48* for Atrial Fibrillation or Flutter, I 50* for Heart Failure; * indicate further specifications).

Practices were recruited between June and November 2006 and practice staff enrolled patients between June 2006 and January 2007. Enrolment of patients with baseline assessment took place after obtaining informed consent during December 2006 and January 2007. Every 
participating GP sent a pseudonymised randomisation document for each patient to an external third party, the Coordination Centre Clinical Trials (CCCT), which supported the project in the conceptual and planning phase (e.g. creation of case report forms, statistical advice) and operational phase (allocation of patients, data management) of the trial. The statistician of the CCCT randomly assigned patients, based on a computer-generated list, to either the intervention or usual care on a weekly ongoing basis. Randomisation was stratified by a "Pocock algorithm" including the number and status of participating patients per practice and arm. Status was defined as whether patients participated in the previously conducted train the trainer study which ended in May 2006 [24]. After randomisation, each randomisation document was sent back to the practice with the result of the assignment. The nature of the intervention ensured that all participants were unblinded once assigned. The third party concealed intervention allocations from the practicebased intervention team until shortly before intervention commencement in February 2007. No interim analyses were conducted during the observation period, with the exception of data collection on heart failure medication for pharmacotherapy feedback. Neither the study statisticians nor the data monitoring committee saw personalised data or had any form of contact with study participants.

\section{Intervention}

Patients randomised to the intervention received complex, structured case management by a trained doctor's assistant (DA) [21]: The design of the intervention addressed the 4 of the 6 elements of the CCM (delivery system design, self-management support, decision support, clinical information systems) [19]: DAs completed 6 hours of theoretical and practical training before conducting regular patient monitoring for 1 year by telephone (patients with NYHA functional status III or IV three-weekly versus I or II six-weekly) and by 3 home visits for all patients. DAs gave feedback of the results of the monitoring and screening to their employing GP. The programme included the use of a CPG, a patient leaflet according to the national CPG, booklets and tailored diaries. Further details of the intervention have been described previously [17,19,21]. Additionally, GPs received graphically depicted individual performance feedback on evidence-based pharmacotherapy (from data of baseline documentation) as described in a preceding trial [24].

For patients in the control (usual care) group, no case management was applied.

\section{Objectives}

In a phase II trial $[14,15]$, we explored whether a comprehensive case management intervention would improve patients' health-related quality of life (QoL), heart failure self-care, and patient-reported quality of care. Furthermore, we obtained data on hospital admissions and mortality.

\section{Outcome measures}

For generic QoL we used the German version of the multidimensional SF-36 [25]. For disease-specific QoL we used the German version of the Kansas City Cardiomyopathy Questionnaire (KCCQ) [26], which has been shown to be a responsive instrument [27].

The SF-36 questionnaire consists of eight dimensions: Physical functioning, role functioning (physical), bodily pain, general health perceptions, vitality, social functioning, role functioning (emotional), and mental health. SF36 scores are converted to a (T-) scale of 0 to 100 , with higher scores indicating a higher QoL. The KCCQ quantifies several health status domains including physical limitations, symptoms (stability, frequency, and burden), selfefficacy, (mental) quality of life, and social function. Each scale is transformed to a score of between 0 and 100, with higher scores indicating superior health status. To summarise the multiple domains of health status quantified by the KCCQ, an overall summary score (KCCQ-os) has been developed that includes the physical limitation, symptoms, quality of life, and social function domains of the KCCQ: A mean five-point change in the scales of the SF-36 [28] and in the KCCQ-os [29] is regarded as clinically significant.

The European Heart Failure Self-care Behaviour Scale (EHFScBS) is a 12-item, self-administered questionnaire that covers items concerning the self-care behaviour of patients with heart failure, for example, daily weighing, fluid restriction, exercise or contacting a health care provider. Scores range from 1-5 (12-60), with low scores implying better self-care behaviour [30].

The self-administered extended Patient Assessment of Chronic Illness Care (PACIC-5A) instrument has been proven to be a practical, reliable and valid tool to measure quality of chronic care according to the elements of the CCM [31-34]. The PACIC-5A questionnaire asked patients 20 questions about important elements of chronic care, e.g. thinking about treatment choices, things that can be done to improve health, goals and treatment plans etc. The 5 subscales of the PACIC domain are patient activation, delivery system/practice design, goal setting/tailoring, problem solving/contextual, and follow-up/coordination. Six additional items measure given behavioural counselling according to the " 5 A" principles (five subscales: assess, advise, agree, assist and arrange) regarding different chronic conditions according to the U.S. Preventive Taskforce recommendations [35,36]. All 26 items are scored on a 5-point Likert scale ranging from 1 (almost never) to 5 (almost always). 
Summary scores are generated for chronic care in accordance with the CCM and for the counselling according to the $5 \mathrm{~A}$, with higher scores indicating a higher accordance.

\section{Data collection and management}

GPs received an initiation visit by a study nurse including an introduction to the trial's investigator file. GPs collected and documented clinical data (history, current clinical status, lab results, ECG, detailed medication for assessment of guideline adherence etc.), discontinuation of the study by the patient, and death of the patient on pre-specified case report forms (CRFs) according to the Basic Clinical Dataset (BCD) of the Competence Network Heart Failure [22]. NT-proBNP levels at baseline were determined at the laboratory of the local university hospital using the Elecsys 2010 analyser from Roche Diagnostics, Germany. GPs also documented primary care activity by the number of practice attendances, referrals to a cardiologist, and hospital stays. The CRFs were sent to the responsible Coordination Centre Clinical Trials (CCCT), where data management was performed [22]. Parallel to the baseline and follow-up documentation after 12 months, patient-reported questionnaires were handed out by DAs. Patients were asked to return the questionnaires to the relevant DA in a pre-specified envelope within seven days. DAs then sent the questionnaires back to the study centre to enable the study nurse to monitor the progress of study documentation and intervene, e.g. by calling, if necessary. All questionnaires were then sent to the CCCT by the study team.

\section{Calculation of sample and effect size}

The primary objective of this study was to explore the effectiveness of the CM intervention. Funding preconditions allowed a maximum total sample size of 200 eligible participants. Assuming an attrition rate of $30 \%$ due to loss to follow-up and death [1], we expected a total of 140 $(2 \times 70)$ patients. Given this sample size, an effect of about 0.45 could be detected using a one-sided t-test with a significance level of $5 \%$ and a power of $80 \%$. Since this study was a pilot-trial, a one-sided t-test was chosen. The intervention would only be further investigated if it had a positive effect on QoL. For quality of life (on the physical functioning scale [28]) between the interventional and control arm at 12-months follow-up, an effect size of about 0.45 corresponds to a clinical difference [37] of about 9 points with a standard deviation of 20.6 suggested from available recommendations [28].

\section{Statistical methods}

Descriptive methods were used for the analysis of the primary and secondary outcomes, including the calculation of appropriate summary measures of the empirical distri- bution (mean, standard deviation, median, minimum, maximum for continuous variables, and frequencies and percentages for categorical variables) as well as calculation of descriptive two-sided p-values for group comparisons. For continuous variables, analyses of covariance (ANCOVA) - adjusted for baseline score, age, gender, and practice type - were performed. Interaction terms for group and gender as well as for group and practice type were included in preliminary models. However, these effects were uniformly non-significant and were removed from subsequent models. For binary variables, logistic regression models were computed. Differences between the groups regarding variables of health care utilisation (e.g. practice attendances during follow-up) were analysed using t-test for normally distributed data and using Mann-Whitney-U-test otherwise. The statistical significance was set at 0.05 . All analyses were performed using SPSS version 16.0.2 (SPSS Inc.).

\section{Ethical approval}

This study was ethically approved by the Institutional review boards of the medical faculty of the University of Heidelberg and Medical Association of the state of Baden-Württemberg.

\section{Results}

\section{Participants' flow and characteristics}

Figure 1 shows the flow of participating primary care physicians and patients through the trial. We approached a total of 252 physicians from 170 practices in a single mail-out in June 2006. Of these, 207 did not respond; 12 physicians expressed an interest but did not take part: 1 lost interest, 11 refused due to work load or personal reasons; and 2 physicians failed to find eligible patients. Therefore, 31 physicians from 29 practices participated. Between June and November 2006, these physicians screened 10653 patients for eligibility. Of these, 10397 failed to meet inclusion criteria, 45 eligible patients refused to participate, 4 did not show up for informed consent, 3 were admitted to hospital at time of inclusion, 2 died before informed consent, 2 lived "too far away" and 1 was judged by the treating physician as being unfit to participate.

The 31 participating physicians recruited 199 eligible patients: 99 patients were randomised to case management and 100 to usual care during December 2006 and January 2007. Once allocated to the case management, 2 participants immediately withdrew their consent rendering data collection at baseline impossible. Seventeen patients were ultimately lost to follow-up, 10 in the case management group and 7 in the usual care group, 5 patients died in each group (for details see Figure 1). Table 1 shows the characteristics of practices and staff. 


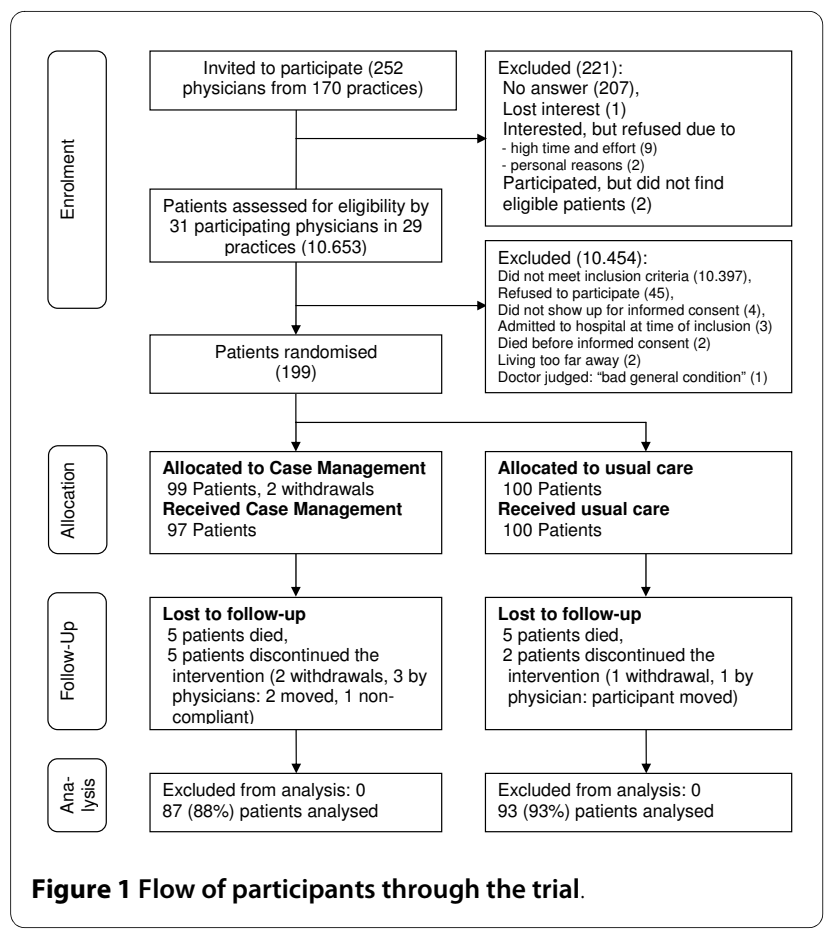

Table 2 shows the baseline characteristics for participants in the intervention and control group regarding sociodemographic, heart failure specific, comorbidity and treatment variables.

\section{Interventions}

All of the participating DAs attended the training sessions, which were held at the local university.

Adjusted for loss to follow-up (5 patients died and 5 discontinued), 97 patients from the case management needed to receive $819(100 \%)$ telephone monitoring sessions and $272(100 \%)$ home visits according to their NYHA functional status: $786(96.0 \%)$ and 269 (98.9\%) of these case management interventions were finally conducted, respectively. Mean durations (SD; range) of the available overall $740(90.3 \%)$ telephone monitoring sessions and the 3 available overall 256 (94.1\%) home visits were $10(5 ; 2-38)$, and $55(14 ; 30-120), 53(16,18-90)$ and 51 (17; 21-90) minutes, respectively. The mean (SD; range) overall travel time for the home visits took 14 (15; $0-105)$ minutes. Reporting to the GP took $7(6 ; 0-45)$, and 13 (6; 3-40), 15 (15; 2-75) and $12(9 ; 3-50)$ minutes, respectively. Missed telephone monitoring sessions were scheduled in the last month of the follow-up period. Adding up the time for telephone monitoring, travel time, home visits, and reporting during the 12-month followup resulted in a mean (SD) overall time of 5.2 (2.0) hours per patient for patients in NYHA functional status I or II and 6.7 (2.4) hours per patient for patients in NYHA functional status III.
Table 1: Baseline characteristics of all 31 general practitioners (GPs) and 31 doctors' assistants (DAs) from 29 practices in Northern Baden.

\begin{tabular}{cl}
\hline Practice factors at baseline & (n = 29) \\
\hline Practice type & $10(34)$ \\
Single & $19(66)$ \\
Group practice & \\
\hline Location & $14(48)$ \\
rural & $5(17)$ \\
suburban & $10(35)$ \\
urban & \\
\hline List size (patients per quarter*) & \\
$0-1000$ & $6(19)$ \\
$1001-1500$ & $11(36)$ \\
$>1500$ & $12(45)$ \\
\hline Medical staff & $(\mathrm{n}=31)$ \\
\hline
\end{tabular}

No. of GPs per practice

$\begin{array}{ll}1 & 10(32) \\ 2 & 14(45) \\ 3 & 4(13) \\ 4 & 3(10)\end{array}$

\begin{tabular}{ll}
\hline No. of DAs in practice & $11(35)$ \\
$1-3$ & $16(52)$ \\
$4-6$ & $4(13)$ \\
$7-11$ & \\
\hline Mean age of in years (SD) & $50.6(9.0)$ \\
GPs & $33.3(9.6)$ \\
DAs & \\
\hline Female & $6(19)$ \\
GPs & $31(100)$ \\
DAs & $16.3(9.0)$ \\
\hline $\begin{array}{l}\text { Certification of GPs since mean } \\
\text { years (SD) }\end{array}$ \\
\hline $\begin{array}{l}\text { DAs work experience since mean } \\
\text { years (SD) }\end{array}$ \\
\hline
\end{tabular}


Table 1: Baseline characteristics of all 31 general practitioners (GPs) and 31 doctors' assistants (DAs) from 29 practices in Northern Baden. (Continued)

\begin{tabular}{ll}
\hline Participation of GP in & \\
Disease management & $29(94)$ \\
programmes & \\
Quality management programme & $18(58)$
\end{tabular}

DA: Doctor's assistant; GP: General practitioner

Values represent number (percentages) of practices unless stated otherwise.

*In German ambulatory care, administration is organized by the Association of Statutory Health Insurance Physicians in 4 accounting periods per year, i.e. patients register in a practice (formally at a physician) in quarters

\section{Quality of life, behaviour change and quality of chronic illness care}

The summary scores of the patient-reported outcomes are displayed in Table 3. Between group differences $(95 \% \mathrm{CI})$ at the 12-month follow-up of the physical and mental component scale of SF-36 were minimal: -0.3 ($3.0 ; 2.5)$ and $-0.1(-3.4 ; 3.1)$. The physical functioning scale of the SF-36 (outcome for sample size calculation, see methods) showed a small, non-significant improvement in favour of the case management group (between group difference: $0.9(95 \% \mathrm{CI}-5.0 ; 6.8)$. With the exception of the vitality scale $(6.6 ; 95 \% \mathrm{CI} 1.8 ; 11.3 ; \mathrm{P}=0.008)$ there were no significant group differences in the SF-36 scales (data not shown in the table).

KCCQ domains were compared for 87 intervention patients and 93 controls (93\% of surviving intervention patients and $98 \%$ of surviving controls) (Figure 1 and Table 3). Between group differences (95\%CI) for the KCCQ overall summary scores favoured CM: 1.7 (-3.0; 6.4). Significant (positive) time effects were found in the case management group for self-efficacy $(6.5$; 95\%CI 1.6; 11.3 ) and social limitation $(5.1 ; 95 \%$ CI $0.2 ; 10.1$ ) (not shown in the table).

Heart failure self-care behaviour scores (EHFScBS) were analysable for 65 intervention patients and 78 controls (69\% of surviving intervention patients and $82 \%$ of surviving controls), with significant group differences favouring the case management group (-3.6; 95\%CI -5.7; 1.6, Cohen's d 0.55, $\mathrm{P}=0.001$, see Table 3).

Significant between group differences were found for quality of chronic illness care (PACIC) and behaviour counselling (PACIC-5A) $(0.5$; 95\%CI 0.3-0.7; $\mathrm{P}=0.000$, and $0.5 ; 95 \% \mathrm{CI} 0.3-0.8 ; \mathrm{P}=0.000)$, with moderate effect sizes (Cohen's d 0.7 for each summary score).

\section{Prescribing behaviour, hospital admissions and primary care activity}

High prescription rates at baseline of drugs with good evidence for health outcomes (ACE inhibitor or A2RA, $\beta$ - blocker, aldosterone antagonists) indicated an antecedent high guideline adherence by physicians; the increases in favour of the intervention group were non-significant (see Additional file 1).

For both groups, heart failure admissions during the pre-observation period were higher than during followup (36 vs. 35 cases): 18 heart failure admissions were observed in 11 patients in the intervention group while 9 were recorded by 7 patients in the control group, respectively (Additional file 1); this was a non-significant difference.

We analysed available primary care activity data during the observation period for 84 patients of the case management group and for 89 patients in the control group. The number of all-cause practice attendances was high at baseline and increased significantly during the follow-up in the intervention group (Mean (SD): 27.6 (16.1) vs. 23.9 (19.2), $\mathrm{p}=0.02)$, but neither the number of practice attendances due to heart failure nor of contacts to cardiologists changed (Additional file 1).

\section{Discussion \\ Summary of main findings}

The intervention failed to improve the overall generic and disease-specific QoL. Nonetheless, we found significant improvements regarding patient-reported quality of care and CHF self-care. While showing low mortality rates ( $~ 5 \%$ in both groups) and decreasing heart failure hospital admissions, there was a significant increase in overall practice attendances in the intervention group but no change in contacts with cardiologists. The case management intervention was found to be feasible for the doctors' assistants to conduct. The following structured discussion also refers the exploratory character of the study and to the taxonomy and framework of chronic illness care as outlined in the introduction $[4,18]$.

\section{Possible mechanisms of findings and their relation to other studies}

The relatively high quality of life scores at baseline are similar to a large, multinational sample of outpatients with CHF (KCCQ-os: $66.2 \pm 20.6$ ) [38]. Our findings could partly reflect the antecedent high level of chronic care and self-care in our selected sample of physicians and patients with stable CHF (with ascertained left ventricular systolic dysfunction). This is supported by the finding of high evidence-based pharmacotherapy compared to landmark studies [39] and to recent clinical trials in secondary care [40], and by the level of chronic illness care and counselling [34], and good self-care (as shown in Table 3) $[6,12,30]$. However, given the social structure in Germany [41], the sample was skewed towards patients in lower socioeconomic classes but this is typically the case for primary care [42]. 
Table 2: Baseline comparison of intervention $(n=97)$ and control group patients $(n=100)$.

\begin{tabular}{|c|c|c|}
\hline & Intervention group $(\mathbf{n}=97)$ & Control group $(n=100)$ \\
\hline Mean (SD; Range) number of patients per practice & $3.2(1.2 ; 1-6)$ & $3.2(1.7 ; 1-8)$ \\
\hline \multicolumn{3}{|l|}{ Practice type } \\
\hline single & $35(36.1)$ & $38(38.0)$ \\
\hline group & $62(63.9)$ & $62(62.0)$ \\
\hline \multicolumn{3}{|l|}{ List size (patients per quarter) } \\
\hline $0-1000$ & $22(22.7)$ & $26(26.0)$ \\
\hline $1001-1500$ & $25(36.1)$ & $22(22.0)$ \\
\hline$>1500$ & $40(41.2)$ & $42(42.0)$ \\
\hline Male sex & $69(71.1)$ & $74(74.0)$ \\
\hline Mean (SD) age (years) & $70.4(10.0)$ & $68.9(9.7)$ \\
\hline Living alone & $26(26.3)$ & $27(27.0)$ \\
\hline Social class*: & $(n=81)$ & $(n=84)$ \\
\hline lower, & 26 (32.1), & 25 (29.8) \\
\hline middle, & 47 (58.0), & 52 (61.9), \\
\hline upper class & $8(9.9)$ & $7(8.3)$ \\
\hline
\end{tabular}

Participation of GP in Train the trainer-trial (GP received an)

\begin{tabular}{lcc}
\hline intensive educational intervention & $14(14.4)$ & $18(18.0)$ \\
\hline control educational intervention & $9(9.3)$ & $10(10.0)$ \\
\hline no educational intervention & & $72(72.0)$
\end{tabular}

NYHA-functional class (according to GP)

\begin{tabular}{lll}
\hline I & $1(1.0)$ & $5(5.0)$ \\
\hline II & $63(64.9)$ & $67(67.0)$ \\
\hline III & $33(34.0)$ & $27(27.0)$ \\
\hline IV & 0 & $1(1.0)$ \\
\hline Mean (SD) LVEF & $35.7(7.5)(\mathrm{n}=83)$ & $37.6(6.7)(\mathrm{n}=88)$ \\
\hline Main cause of CHF & & $47(47.0)$ \\
\hline ischemic & $46(47.4)$ & \\
\hline
\end{tabular}


Table 2: Baseline comparison of intervention $(n=97)$ and control group patients $(n=100)$. (Continued)

\begin{tabular}{|c|c|c|}
\hline non-ischemic & $51(52.6)$ & $53(53.0)$ \\
\hline Mean (SD) duration (years) of $\mathrm{CHF}$ & $6.2(4.6)(n=79)$ & $6.8(6.3)(n=74)$ \\
\hline \multicolumn{3}{|l|}{ Localisation of CHF } \\
\hline Left & $61(62.9)$ & $67(67.0)$ \\
\hline Left and right & $33(34.0)$ & $31(31.0)$ \\
\hline Unknown & $3(3.1)$ & $2(2.0)$ \\
\hline \multicolumn{3}{|l|}{ Cardiovascular interventions } \\
\hline PTCA/Stent (any) & $29(29.9)$ & $36(36.0)$ \\
\hline Bypass (any) & $21(21.6)$ & $21(21.0)$ \\
\hline Pacemaker (right ventricular) & $16(16.5)$ & $16(16.0)$ \\
\hline Pacemaker (biventricular) & $7(7.2)$ & $8(8.0)$ \\
\hline ICD & $11(11.3)$ & $21(21.0)$ \\
\hline Prosthetic heart valve (any) & $5(5.2)$ & $7(7.0)$ \\
\hline Reanimation/Defibrillation & $8(8.2)$ & $6(6.0)$ \\
\hline
\end{tabular}

Medical conditions

\begin{tabular}{lcc}
\hline Atrial fibrillation & $25(25.8)$ & $29(29.0)$ \\
\hline PAD & $17(17.5)$ & $17(17.0)$ \\
\hline Cerebrovascular disease & $22(22.7)$ & $16(16.0)$ \\
\hline Asthma & $7(7.2)$ & $5(5.0)$ \\
\hline COPD & $25(25.8)$ & $27(27.0)$ \\
\hline Depression & $22(22.7)$ & $17(17.0)$ \\
\hline Cardiovascular risk factors & & $35(35.0)$ \\
\hline Diabetes mellitus & $32(33.0)$ & $78(78.0)$ \\
\hline Hypertension & $78(80.4)$ & \\
\hline
\end{tabular}


Table 2: Baseline comparison of intervention $(n=97)$ and control group patients $(n=100)$. (Continued)

\begin{tabular}{|c|c|c|}
\hline Dyslipidemia & $63(64.9)$ & $75(75.0)$ \\
\hline History of infarction before 60 years & $18(18.6)$ & $16(16.0)$ \\
\hline Ex-/smoker (Ex: since at least 6 months) & $38 / 9(39.2 / 9.3)$ & $42 / 14(42.0 / 14.0)$ \\
\hline Mean number (SD) of drinks per week & $3.9(5.5)$ & $4.7(9.2)$ \\
\hline Creatinine-Clearance: Mean (SD) GFR (ml/min) ${ }^{* *}$ & $71.6(31.4)(n=96)$ & $71.6(35.1)$ \\
\hline Stage of renal dysfunction & $(n=96)$ & \\
\hline $\mathrm{GFR} \geq 60 \mathrm{ml} / \mathrm{min}^{* *}$ & $54(56.2)$ & $57(57.0)$ \\
\hline GFR $30-59 \mathrm{ml} / \mathrm{min}^{* *}$ & 39 (40.6) & $37(37.0)$ \\
\hline $\mathrm{GFR} \leq 29 \mathrm{ml} / \mathrm{min}^{* *}$ & $3(3.1)$ & $6(6.0)$ \\
\hline Mean (SD) level of NT-pro-BNP [Median, IQR] in pg/ml & $2222.5(5282.2)[1010.5,1750](n=94)$ & $1828.6(2914.9)[930,1712](n=96)$ \\
\hline \multicolumn{3}{|l|}{ Drugs at baseline included: } \\
\hline ACE inhibitor or A2RA & $91(93.8)$ & $95(95.0)$ \\
\hline$\beta$-blocker & $70(72.2)$ & $84(84.0)$ \\
\hline ACE inhibitor/A2RA and $\beta$-blocker & $66(68.0)$ & $80(80.0)$ \\
\hline Spironolactone/Eplerenone & $32(33.0)$ & $26(26.0)$ \\
\hline Loop diuretics & $60(61.9)$ & $59(59.0)$ \\
\hline Thiazide diuretics & $34(35.1)$ & $41(41.0)$ \\
\hline Cardiac glycosides & $25(25.8)$ & $26(26.0)$ \\
\hline Statins & $57(58.8)$ & $58(58.0)$ \\
\hline Other lipid lowering drugs & $11(11.3)$ & $14(14.0)$ \\
\hline Aspirin $(100-300 \mathrm{mg} / \mathrm{d})$ & $38(39.2)$ & $43(43.0)$ \\
\hline Clopidogrel & $5(5.2)$ & $5(5.0)$ \\
\hline $\begin{array}{l}\text { Phenprocoumon (Vitamin K Antagonist: equivalent to } \\
\text { Warfarin) }\end{array}$ & $41(42.3)$ & $46(46.0)$ \\
\hline
\end{tabular}

Values represent numbers (percentages) of patients unless stated otherwise.

* Social Class according to modified German Winkler-index [57] (lower class: 3-7; middle class: 8-14; upper class: 15-21)

**Estimation of the GFR according to the formula of Cockroft and Gault; 
Table 3: Mean (SD) scores for groups for generic (SF-36) and disease-specific (KCCQ) quality of life, for self-care (EHFScBS), for chronic illness care (PACIC) and health counselling (PACIC-5A) at baseline and at 12 months' follow-up.

\begin{tabular}{|c|c|c|c|c|c|c|c|}
\hline & & $\begin{array}{l}\text { Intervention } \\
\text { (HICMan) group }\end{array}$ & No & Control group & No & $\begin{array}{l}\text { Effect Mean Difference** } \\
(95 \% \mathrm{CI}) \text {, Cohen's d }\end{array}$ & P value** \\
\hline \multicolumn{8}{|l|}{ SF-36 } \\
\hline \multirow[t]{2}{*}{ physical composite score } & at baseline & $36.4(11.0)$ & 78 & $36.9(10.1)$ & 82 & & \\
\hline & at follow-up** & $38.0(8.6)$ & 61 & $38.3(8.6)$ & 70 & $-0.3[-3.0,2.5], 0.04$ & 0.857 \\
\hline \multirow[t]{2}{*}{ mental composite score } & at baseline & $45.8(11.9)$ & 78 & $47.6(12.8)$ & 82 & & \\
\hline & at follow-up** & $46.5(9.9)$ & 61 & $46.6(9.9)$ & 70 & $-0.1[-3.4,3.1], 0.01$ & 0.929 \\
\hline \multirow[t]{2}{*}{ KCCQ overall summary score } & at baseline & $65.4(22.6)$ & 96 & $64.7(22.7)$ & 100 & & \\
\hline & at follow-up** & $68.0(16.9)$ & 87 & $66.3(17.2)$ & 93 & $1.7[-3.0,6.4], 0.10$ & 0.477 \\
\hline \multirow[t]{2}{*}{ EHFScBS* } & at baseline & $25.4(8.4)$ & 65 & $25.0(7.1)$ & 78 & & \\
\hline & at follow-up** & $21.2(6.4)$ & 65 & $24.8(6.7)$ & 78 & $-3.6[-5.7,-1.6], 0.55$ & 0.001 \\
\hline \multirow[t]{2}{*}{ PACIC overall score } & at baseline & $3.2(0.9)$ & 89 & $3.2(0.8)$ & 97 & & \\
\hline & at follow-up** & $3.8(0.7)$ & 80 & $3.3(0.7)$ & 89 & $0.5[0.3,0.7], 0.72$ & 0.000 \\
\hline \multirow[t]{2}{*}{ PACIC-5A overall score } & at baseline & $3.2(0.9)$ & 89 & $3.2(0.9)$ & 97 & & \\
\hline & at follow-up** & $3.8(0.7)$ & 79 & $3.3(0.7)$ & 89 & $0.5[0.3,0.8], 0.72$ & 0.000 \\
\hline
\end{tabular}

*Scores range from 12-60; low scores imply better self-care behaviour.

**Based on analysis of covariance (ANCOVA) comparing results between groups at 12 months, adjusted for baseline score, age, gender, practice size (single vs. group-practice and list size) without interaction terms. All P values are descriptive.

Observed mortality and heart failure hospitalisation rates were lower than reported previously $[1,13]$, and a recent population study shows a trend of decreased mortality attributable to improvements in treatment and prevention [43]. Comparing our study with a meta-analysis regarding heart failure hospital admissions, rates for case management vs. usual care were $21.7 \%$ (18/83) vs. $10.4 \%$ (9/86) in our study (during 12 months follow-up) and $18.0 \%(94 / 523)$ vs. $29.4 \%(155 / 528)$ (with different followup periods from 3 to 12 months) [11]. While our study was not powered to this outcome, our findings resemble those of a recent larger trial, where an intensive disease management approach increased heart failure hospital admissions, where the authors concluded that the threshold may have been too low to admit patients to the hospital [13]. While GPs in our trial received an introductory clinical practice guideline, behaviour counselling and pharmacotherapy feedback, they were not specifically trained in clinical issues relating to thresholds for hospital admissions and we did not target physicians' behaviour regarding health care utilisation (referral or hospital admission). However, our intervention might have caused the unintended effect of increased hospitalisation (at higher costs). Whether our observation is an effect of the intervention cannot be concluded. The observed difference could have been by chance, due to the Hawthorne Effect among practice staff and in consequence undue admissions, or it could be a marker of higher quality of care. A recent review suggests that disease management interventions that do not involve efforts to improve physician care are less effective [44]. In our trial, the physician care targets were evidence-based pharmacotherapy (with little room for improvement) and counselling, and providing a basis for decision through $\mathrm{CM}$ with feedback of information to the physician. 
Reviews of trials of case management programmes for patients with CHF have shown mixed results relating to effects on hospital admissions, mortality and QoL [9-11]. Furthermore, these studies have used a diversity of outcome instruments, which hinders comparability, e.g. disease-specific QoL has usually been measured with the Minnesota living with Heart Failure Questionnaire (MIlwHFQ), but generic QoL with the SF-36. Previous studies have shown variability in the complexity of case management (elements of the intervention, integration of care sectors, education and training of case managers, and patient empowerment): While overall positive effects on predominantly disease-specific QoL were found in the short term (3 to 6 months) follow-up [45-48], the results for longer follow-ups (9 months to 1 year) were predominantly neutral $[5,12,49-52]$ : Typically, short-term positive effects on quality of life were observed in hospitalised and acutely ill patients, who started with low scores at baseline enabling the short-term effects in comparison to control [46-48]. However, our patient sample included stable chronic systolic heart failure and, in relation to their age and disease, relatively high quality of life scores at baseline [28,52]. Regarding generic QoL, our results suggest that an effect size of 5 points would not be reached irrespective of the power of the sample size. Regarding disease-specific QoL, as the upper CI exceeds 5 points (KCCQ-os, see Table 3), results can be regarded as inconclusive. Nevertheless, QoL did not decrease in both groups after 1 year, which may be seen as a treatment (and observational) effect, as the natural course of patients with $\mathrm{CHF}$ and normal population shows a decline in QoL [53].

Two previous randomised controlled trials with the same (1 year) follow-up period and similar sample sizes, sex and age profiles showed clinically relevant effects on QoL and hospital admissions $[4,5,12]$. They differed from our study in that the interventions were conducted mainly in a secondary care setting and the targeted subgroups of heart failure patients included patients in more acute phases, with a higher functional and objective disease severity (exclusively NYHA III and IV patients, stronger impaired systolic function). While comorbidity was similar, our sample showed higher rates of diagnostic measures and causal therapies indicated by cardiovascular interventions (PTCA/Stent: 33\% vs. 15\%, CABG: 21\% vs. $24 \%$, Pacemaker: $24 \%$ vs. $9 \%$ ) (Table 2, [12]). However, the main novel aspect of our trial relates to the staff who delivered case management, the intervention content, the methods of communication, and the intensity and complexity of the intervention [4]: Doctors' assistants and GPs vs. cardiologists and specialised nurses were involved. While all programmes had a similar frequency of face-toface contacts, the quality and the intensity of the medical care (e.g. investigations [12]) and educational content were higher in other studies [5,12,54]. Knowing these contextual differences with regard to training level and skills of staff, our intervention included a provider intervention (training of doctors' assistants and introduction for GPs) and used an elaborated standardised case management concept enabling doctors' assistants to deliver case management. It addressed 4 of the 6 domains of the chronic care model [18]: delivery system design (giving a doctor's assistant a new role), self-management support (by counselling and the questions included in the monitoring lists), decision support (by patient and physician guidelines and pharmacotherapy feedback) and clinical information systems (a registry, patient booklets).

Heterogeneous results regarding QoL have been found in other primary care-based patient populations: In cardiovascular high risk patients, improvements in many scales of generic QoL have been found in primary carebased interventions $[52,55]$. However, either the baseline level was low leaving more room for improvement (physical functioning) [52], or, if baseline was high, the relative improvements (in a big sample) were small, and probably not clinically relevant [55].

\section{Strengths and limitations of the study}

The strengths of the study are that many aspects of the trial promoted high internal validity. Randomisation was concealed and conducted by a third party; there were reasonably equivalent groups of patients at baseline (with the exception of differences in the prescription rates of $\beta$ blockers) and good follow-up of patients (93-95\% for the potential primary outcome). However, a weakness is that it was impossible to blind providers to treatment group, which may have biased their activity as well as patient responses to questionnaires. Furthermore, randomisation was performed at the patient level and all GPs received an introduction to guideline-oriented management of CHF and counselling, which may have led to some contamination between the interventions. While a cluster randomised controlled trial might have mitigated contamination, we believe any bias was limited because the main aspects of the intervention were performed by doctor's assistants and instruments (monitoring lists, screening instruments, booklets, patient information) and were delivered to each individual patient. If there was a bias, we believe that the consequence is that the measured effect of the intervention may be underestimated.

The baseline characteristics of GPs and the pharmacotherapy profile indicate a non-representative sample of physicians. Moreover, group practices dominate our sample while, in Germany, solo practices are most common (64.1\%) [56]. Also, participating GPs showed some signs of above average performance and early adoption of new methods of practice, for example participating in disease management programmes. Furthermore, some of the 
GPs and their patients participated in a preceding trial aimed at optimisation of heart failure care in general practice [24]. However, baseline prescription rates were high also in that study, so it is probably the selection of patients with ascertained left ventricular systolic dysfunction and subsequent prescription of evidence-based pharmacotherapy that is observed.

Considering these aspects of internal and external validity, further evaluation in a larger representative sample for robust data is needed to draw definitive conclusions on the effectiveness on QoL, mortality and health service utilisation.

\section{Conclusions}

This phase II trial demonstrates some positive effects of primary care-based case management on self-care and quality of care in chronic, stable patients with CHF. The approach was seen as feasible by practice staff $[17,19]$.

Improved quality of chronic care and CHF self-care could be regarded as important and targeted outcomes for an intervention in elderly, multimorbid patients with $\mathrm{CHF}$ in primary care. The CM intervention was successfully adapted for primary care settings for this patient group and while the approach could be augmented by the use of exercise training programmes which are generally known to be effective, these are not always feasible. It is possible that patients with more advanced CHF might profit from a CM model approach, with pre-defined involvement of specialist and integrated care approaches, including (post-) discharge approaches.

\section{Additional material}

Additional file 1 Guideline Adherence, mortality, hospital admissions, practice attendances and referrals to cardiologist at baseline or during 12 months' pre-observation period and at or during 12 months' follow-up. Frequencies (percentages) are shown for groups unless stated otherwise.

\section{Abbreviations}

A2RA: Angiotensin-2 receptor antagonist; ACE: Angiotensin converting enzyme; CCCT: Coordination Centre Clinical Trials; CCM: Chronic Care Model; CHD: Coronary heart disease; CHF: Chronic (systolic) heart failure; $\mathrm{Cl}$ : Confidence interval; COPD: Chronic obstructive pulmonary disease; CPG: Clinical practice guideline; EHFScBS: European Heart Failure Self-care Behaviour Scale; GFR: Glomerular filtration rate; GP: General practitioner; HICMan: Heidelberg Integrated Case management; ICD: Implantable cardioverter defibrillator; IQR: Inter Quartile Range; KCCQ: Kansas City Cardiomyopathy Questionnaire; LVEF: Left ventricular ejection fraction; LVSD: Left ventricular systolic dysfunction; NTproBNP: N-terminal Brain Natriuretic Peptide; NYHA: New York Heart Association; OR: Odds ratio; PACIC: Patient Assessment of Chronic Illness Care; PAD: Peripheral arterial disease; PC: Primary Care; PHQ-9: Depression module of the Patient Health Questionnaire; PTCA: Percutaneous Transluminal Coronary Angioplasty; QoL: (Health-related) Quality of life; RCT: Randomised controlled trial; SF-36: MOS 36-item short-form health survey.

\section{Competing interests}

The authors declare that they have no competing interests.

\section{Authors' contributions}

FPK, TMT and JS designed the study. CUK, KH and FPK analysed the results. Al authors interpreted the results. FPK wrote the manuscript, and is the guarantor. All authors contributed to writing revisions and approved the final manuscript.

\section{Acknowledgements}

We thank all participating practitioners and doctors' assistants for their participation in the study, which entailed recruiting patients, collecting data and conduct of case management. Special thanks go to the study participants.

We thank Annika Baldauf, study nurse, for her extraordinary work; Christiane Muth, research fellow, Institute for General Practice, Chronic Care and Health Services Research, University of Frankfurt, and Jochen Gensichen, director, Institute for General Practice, University hospital Jena, for the provision of parts of the monitoring and training concepts of Case management for heart failure; Dieter Schellberg, Beate Wild and Wolfgang Herzog for advice regarding the trial design and application for funding, all Department of Psychosomatic and General Internal Medicine, University Hospital Heidelberg; Goetz Gelbrich for statistical advice and Christiane Prettin, Angelika Beyer and Bianca Scholze for data management, all CCCT Leipzig

The study was supported by the Competence Network Heart Failure, funded by the German Ministry of Education and Research (BMBF), grant no. 01GI0205/P. Roche Diagnostics, Mannheim, Germany, provided the test kits for the determination of NT-pro-BNP.

\section{Author Details}

1Department of General Practice and Health Services Research, University Hospital Heidelberg, Heidelberg, Germany, ${ }^{2}$ National Primary Care Research and Development Centre, University of Manchester, Manchester, UK, 3 Institute of Medical Biometry and Informatics, University Hospital Heidelberg, Heidelberg, Germany and ${ }^{4}$ Department of Psychosomatic and General Internal Medicine, University Hospital Heidelberg, Heidelberg, Germany

Received: 18 February 2010 Accepted: 17 May 2010

Published: 17 May 2010

\section{References}

1. McMurray JJ, Pfeffer MA: Heart failure. Lancet 2005, 365:1877-1889.

2. Dickstein K, Cohen-Solal A, Filippatos G, McMurray JJ, Ponikowski P, PooleWilson PA, Stromberg A, van Veldhuisen DJ, Atar D, Hoes AW, Keren A, Mebazaa A, Nieminen M, Priori SG, Swedberg K, Vahanian A, Camm J, De Caterina R, Dean V, Dickstein K, Filippatos G, Funck-Brentano C, Hellemans I, Kristensen SD, McGregor K, Sechtem U, Silber S, Tendera M, Widimsky P, Zamorano JL, Tendera M, Auricchio A, Bax J, Bohm M, Corra U, della BP, Elliott PM, Follath F, Gheorghiade M, Hasin Y, Hernborg A, Jaarsma T, Komajda M, Kornowski R, Piepoli M, Prendergast B, Tavazzi L, Vachiery JL, Verheugt FW, Zamorano JL, Zannad F: ESC guidelines for the diagnosis and treatment of acute and chronic heart failure 2008: the Task Force for the diagnosis and treatment of acute and chronic heart failure 2008 of the European Society of Cardiology. Developed in collaboration with the Heart Failure Association of the ESC (HFA) and endorsed by the European Society of Intensive Care Medicine (ESICM). Eur J Heart Fail 2008, 10:933-989.

3. Wal MH van der, Jaarsma T: Adherence in heart failure in the elderly: problem and possible solutions. Int J Cardiol 2008, 125:203-208.

4. Krumholz HM, Currie PM, Riegel B, Phillips CO, Peterson ED, Smith R, Yancy CW, Faxon DP: A taxonomy for disease management: a scientific statement from the American Heart Association Disease Management Taxonomy Writing Group. Circulation 2006, 114:1432-1445.

5. Doughty RN, Wright SP, Pearl A, Walsh HJ, Muncaster S, Whalley GA, Gamble G, Sharpe N: Randomized, controlled trial of integrated heart failure management: The Auckland Heart Failure Management Study. Eur Heart J 2002, 23:139-146

6. Holland R, Brooksby I, Lenaghan E, Ashton K, Hay L, Smith R, Shepstone L, Lipp A, Daly C, Howe A, Hall R, Harvey I: Effectiveness of visits from community pharmacists for patients with heart failure: HeartMed randomised controlled trial. BMJ 2007, 334:1098.

7. Phillips CO, Wright SM, Kern DE, Singa RM, Shepperd S, Rubin HR: Comprehensive discharge planning with postdischarge support for older patients with congestive heart failure: a meta-analysis. JAMA 2004, 291:1358-1367. 
8. Clark RA, Inglis SC, McAlister FA, Cleland JG, Stewart S: Telemonitoring or structured telephone support programmes for patients with chronic heart failure: systematic review and meta-analysis. BMJ 2007, 334:942.

9. Gensichen J, Beyer M, Kuver C, Wang H, Gerlach FM: [Case management for patients with congestive heart failure under ambulatory care--a critical review]. Z Arztl Fortbild Qualitatssich 2004, 98:143-154.

10. Roccaforte R, Demers C, Baldassarre F, Teo KK, Yusuf S: Effectiveness of comprehensive disease management programmes in improving clinical outcomes in heart failure patients. A meta-analysis. Eur J Heart Fail 2005, 7:1133-1144.

11. Taylor S, Bestall J, Cotter S, Falshaw M, Hood S, Parsons S, Wood L, Underwood M: Clinical service organisation for heart failure. Cochrane Database Syst Rev 2005:CD002752

12. de la Porte PWFB, Lok DJA, van Veldhuisen DJ, van Wijngaarden J, Cornel $\mathrm{JH}$, Zuithoff NPA, Badings E, Hoes AW: Added value of a physician-andnurse-directed heart failure clinic: results from the Deventer-Alkmaar heart failure study. Heart 2007, 93:819-825.

13. Jaarsma T, Wal MHL van der, Lesman-Leegte I, Luttik ML, Hogenhuis J, Veeger NJ, Sanderman R, Hoes AW, van Gilst WH, Lok DJA, Dunselman PHJM, Tijssen JGP, Hillege HL, van Veldhuisen DJ, for the Coordinating Study Evaluating Outcomes of Advising and Counseling in Heart Failure $(\mathrm{COACH})$ Investigators: Effect of Moderate or Intensive Disease Management Program on Outcome in Patients With Heart Failure: Coordinating Study Evaluating Outcomes of Advising and Counseling in Heart Failure (COACH). Arch Intern Med 2008, 168:316-324.

14. Campbell M, Fitzpatrick R, Haines A, Kinmonth AL, Sandercock P, Spiegelhalter D, Tyrer P: Framework for design and evaluation of complex interventions to improve health. BMJ 2000, 321:694-696

15. Campbell NC, Murray E, Darbyshire J, Emery J, Farmer A, Griffiths F, Guthrie $B$, Lester H, Wilson P, Kinmonth AL: Designing and evaluating complex interventions to improve health care. BMJ 2007, 334:455-459.

16. Mahler C, Trieschmann J, Szecsenyi J, Rosemann T: [Motivational Aspects of Medical Staff Assistants Regarding Further Education - Results of a Survey] Fortbildungsmotivation von Arzthelferinnen - Ergebnisse einer Befragung. Zeitschrift für Allgemeinmedizin 2007, 83:191-196.

17. Olbort R, Mahler C, Campbell S, Reuschenbach B, Muller-Tasch T, Szecsenyi J, Peters-Klimm F: Doctors' assistants' views of case management to improve chronic heart failure care in general practice: a qualitative study. J Adv Nurs 2009, 65:799-808.

18. Bodenheimer T, Wagner EH, Grumbach K: Improving primary care for patients with chronic illness. JAMA 2002, 288:1775-1779.

19. Peters-Klimm F, Olbort R, Campbell S, Mahler C, Miksch A, Baldauf A, Szecsenyi J: Physicians' view of primary care-based case management for patients with heart failure: a qualitative study. Int $\mathrm{Q}$ Qual Health Care 2009, 21:363-371

20. Rickham PP: Human experimentation. Code of ethics of the world medical association. Declaration of Helsinki. Br Med J 1964, 2:177.

21. Peters-Klimm F, Mueller-Tasch T, Schellberg D, Gensichen J, Muth C, Herzog W, Szecsenyi J: Rationale, design and conduct of a randomised controlled trial evaluating a primary care-based complex intervention to improve the quality of life of heart failure patients: HICMan (Heidelberg Integrated Case Management). BMC Cardiovasc Disord 2007, 7:25.

22. Mehrhof F, Loffler M, Gelbrich G, Ozcelik C, Posch M, Hense HW, Keil U, Scheffold T, Schunkert H, Angermann C, Ertl G, Jahns R, Pieske B, Wachter R, Edelmann F, Wollert KC, Maisch B, Pankuweit S, Erbel R, Neumann T, Herzog W, Katus H, Muller-Tasch T, Zugck C, Dungen HD, Regitz-Zagrosek V, Lehmkuhl E, Stork S, Siebert U, Wasem J, Neumann A, Gohler A, Anker SD, Kohler F, Mockel M, Osterziel KJ, Dietz R, Rauchhaus M: A network against failing hearts-Introducing the German "Competence Network Heart Failure". Int J Cardiol 2009 in press.

23. Peters-Klimm F, Muller-Tasch T, Schellberg D, Remppis A, Barth A, Holzapfel N, Junger J, Herzog W, Szecsenyi J: Guideline adherence for pharmacotherapy of chronic systolic heart failure in general practice: a closer look on evidence-based therapy. Clin Res Cardiol 2008, 97:244-252.

24. Peters-Klimm F, Muller-Tasch T, Remppis A, Szecsenyi J, Schellberg D: Improved guideline adherence to pharmacotherapy of chronic systolic heart failure in general practice - results from a cluster-randomized controlled trial of implementation of a clinical practice guideline. J Eval Clin Pract 2008, 14:823-829.
25. Ware J, Sherbourne CD: The MOS 36-item short-form health survey (SF36). I. Conceptual framework and item selection. Med Care 1992, 30:473-483

26. Green CP, Porter CB, Bresnahan DR, Spertus JA: Development and evaluation of the Kansas City Cardiomyopathy Questionnaire: a new health status measure for heart failure. J Am Coll Cardiol 2000, 35:1245-1255

27. Eurich D, Johnson J, Reid K, Spertus J: Assessing responsiveness of generic and specific health related quality of life measures in heart failure. Health and Quality of Life Outcomes 2006, 4:89.

28. Bullinger M, Kirchberger I: SF-36 Fragebogen zum Gesundheitszustand, Handanweisung. Kirchberger, I. Göttingen, Hogrefe Verlag für Psychologie; 1998.

29. Spertus J, Peterson E, Conard MW, Heidenreich PA, Krumholz HM, Jones P, McCullough PA, Pina I, Tooley J, Weintraub WS, Rumsfeld JS: Monitoring clinical changes in patients with heart failure: A comparison of methods. American Heart Journal 2005, 150:707-715.

30. Jaarsma T, Strömberg A, Martensson J, Dracup K: Development and testing of the European Heart Failure Self-Care Behaviour Scale. The European Journal of Heart Failure 2003, 5:363-370.

31. Glasgow RE, Wagner EH, Schaefer J, Mahoney LD, Reid RJ, Greene SM: Development and validation of the Patient Assessment of Chronic IIIness Care (PACIC). Med Care 2005, 43:436-444.

32. Rosemann T, Laux G, Droesemeyer S, Gensichen J, Szecsenyi J: Evaluation of a culturally adapted German version of the Patient Assessment of Chronic Illness Care (PACIC 5A) questionnaire in a sample of osteoarthritis patients. J Eval Clin Pract 2007, 13:806-813.

33. Wensing M, van Lieshout J, Jung HP, Hermsen J, Rosemann T: The Patients Assessment Chronic Illness Care (PACIC) questionnaire in The Netherlands: a validation study in rural general practice. BMC Health Serv Res 2008, 8:182

34. Szecsenyi J, Rosemann T, Joos S, Peters-Klimm F, Miksch A: German Diabetes Disease Management Programs Are Appropriate for Restructuring Care According to the Chronic Care Model: An evaluation with the Patient Assessment of Chronic Illness Care instrument. Diabetes Care 2008, 31:1150-1154.

35. Goldstein MG, Whitlock EP, DePue J: Multiple behavioral risk factor interventions in primary care. Summary of research evidence. Am J PrevMed 2004, 27:61-79.

36. Whitlock EP, Orleans CT, Pender N, Allan J: Evaluating primary care behavioral counseling interventions: an evidence-based approach. Am J Prev Med 2002, 22:267-284.

37. Peters-Klimm F, Campbell S, Müller-Tasch T, Schellberg D, Gelbrich G, Herzog W, Szecsenyi J: Primary care-based multifaceted, interdisciplinary medical educational intervention for patients with systolic heart failure: lessons learned from a cluster randomised controlled trial. Trials 2009, 10:68.

38. Flynn KE, Lin L, Ellis SJ, Russell SD, Spertus JA, Whellan DJ, Pina IL, Fine LJ, Schulman KA, Weinfurt KP: Outcomes, health policy, and managed care: relationships between patient-reported outcome measures and clinical measures in outpatients with heart failure. Am Heart J 2009, 158:S64-S71.

39. Cleland JG, Cohen-Solal A, Aguilar JC, Dietz R, Eastaugh J, Follath F, Freemantle N, Gavazzi A, van Gilst WH, Hobbs FD, Korewicki J, Madeira HC, Preda I, Swedberg K, Widimsky J: Management of heart failure in primary care (the IMPROVEMENT of Heart Failure Programme): an international survey. Lancet 2002, 360:1631-1639.

40. Gissi-HF I, Tavazzi L, Maggioni AP, Marchioli R, Barlera S, Franzosi MG, Latini R, Lucci D, Nicolosi GL, Porcu M, Tognoni G: Effect of rosuvastatin in patients with chronic heart failure (the GISSI-HF trial): a randomised, double-blind, placebo-controlled trial. Lancet 2008, 372:1231-1239.

41. Knopf H, Ellert U, Melchert HU: [Social class and health]. Gesundheitswesen 1999, 61(Spec No):S169-S177.

42. Thode N, Bergmann E, Kamtsiuris P, Kurth BM: [Predictors for ambulatory medical care utilization in Germany]. Bundesgesundheitsblatt Gesundheitsforschung Gesundheitsschutz 2005, 48:296-306

43. Jhund PS, MacIntyre K, Simpson CR, Lewsey JD, Stewart S, Redpath A, Chalmers JWT, Capewell S, McMurray JJV: Long-Term Trends in First Hospitalization for Heart Failure and Subsequent Survival Between 1986 and 2003: A Population Study of 5.1 Million People. Circulation 2009, 119:515-523. 
44. Coleman K, Mattke S, Perrault PJ, Wagner EH: Untangling Practice Redesign from Disease Management: How Do We Best Care for the Chronically III? Annual Review of Public Health 2009, 30:

45. Rich MW, Beckham V, Wittenberg C, Leven CL, Freedland KE, Carney RM: A multidisciplinary intervention to prevent the readmission of elderly patients with congestive heart failure. N Eng/ J Med 1995, 333:1190-1195.

46. Harrison MB, Browne GB, Roberts J, Tugwell P, Gafni A, Graham ID: Quality of life of individuals with heart failure: a randomized trial of the effectiveness of two models of hospital-to-home transition. Med Care 2002, 40:271-282.

47. Stewart S, Marley JE, Horowitz JD: Effects of a multidisciplinary, homebased intervention on unplanned readmissions and survival among patients with chronic congestive heart failure: a randomised controlled study. Lancet 1999, 354:1077-1083.

48. Kasper EK, Gerstenblith G, Hefter G, Van Anden E, Brinker JA, Thiemann DR, Terrin M, Forman S, Gottlieb SH: A randomized trial of the efficacy of multidisciplinary care in heart failure outpatients at high risk of hospital readmission. J Am Coll Cardiol 2002, 39:471-480.

49. Jaarsma T, Halfens R, Tan F, Abu-Saad HH, Dracup K, Diederiks J: Self-care and quality of life in patients with advanced heart failure: the effect of a supportive educational intervention. Heart Lung 2000, 29:319-330

50. Hughes SL, Weaver FM, Giobbie-Hurder A, Manheim L, Henderson W, Kubal JD, Ulasevich A, Cummings J: Effectiveness of team-managed home-based primary care: a randomized multicenter trial. JAMA 2000, 284:2877-2885.

51. Cline CM, Israelsson BY, Willenheimer RB, Broms K, Erhardt LR: Cost effective management programme for heart failure reduces hospitalisation. Heart 1998, 80:442-446.

52. Khunti K, Stone M, Paul S, Baines J, Gisborne L, Farooqi A, Luan X, Squire I: Disease management programme for secondary prevention of coronary heart disease and heart failure in primary care: a cluster randomised controlled trial. Heart 2007, 93:1398-1405.

53. Hopman WM, Berger C, Joseph L, Towheed T, VandenKerkhof E, Anastassiades T, Adachi JD, loannidis G, Brown JP, Hanley DA,

Papadimitropoulos EA: The natural progression of health-related quality of life: results of a five-year prospective study of SF-36 scores in a normative population. Qual Life Res 2006, 15:527-536.

54. Bruggink-Andre de la Porte P, Lok DJA, van Wijngaarden J, Cornel JH, Pruijsers-Lamers D, van Veldhuisen DJ, Hoes AW: Heart failure programmes in countries with a primary care-based health care system. Are additional trials necessary? Design of the DEAL-HF study. European Journal of Heart Failure 2005, 7:910-920.

55. Lobo CM, Frijling BD, Hulscher ME, Bernsen RM, Grol RP, Prins A, Wouden $J C$ van der: Effect of a comprehensive intervention program targeting general practice staff on quality of life in patients at high cardiovascular risk: a randomized controlled trial. Qual Life Res 2004, 13:73-80.

56. Regional Association of Statutory Health Insurance Physicians: Qualitätsbericht 2006 [Quality report 2006]. 2006 [http:// www.kvbawue.de/uploads/tx userkvbwpdfdownload/ qualibericht 2006 klein.pdf. 26-5-2008

57. Winkler J: Scaling social status in the german national health surveys. RKI-Schriften 1998:69-74

doi: $10.1186 / 1745-6215-11-56$

Cite this article as: Peters-Klimm et al., Case management for patients with chronic systolic heart failure in primary care: The HICMan exploratory randomised controlled trial Trials 2010, 11:56

\section{Submit your next manuscript to BioMed Central} and take full advantage of:

- Convenient online submission

- Thorough peer review

- No space constraints or color figure charges

- Immediate publication on acceptance

- Inclusion in PubMed, CAS, Scopus and Google Scholar

- Research which is freely available for redistribution

Submit your manuscript at www.biomedcentral.com/submit
C BioMed Central 